Abstracta Iranica Abstracta Iranica

Revue bibliographique pour le domaine irano-aryen

Volume 42-43 | 2021

Comptes rendus des publications de 2019-2020

\title{
Valentina Laviola, Martina Massullo (eds.), Mahabbatnāma. Scritti offerti a Maria Vittoria Fontana dai suoi allievi per il suo settantesimo compleanno
}

\section{Sandra Aube}

\section{(2) OpenEdition}

1 Journals

Édition électronique

URL : https://journals.openedition.org/abstractairanica/53936

DOI : 10.4000/abstractairanica.53936

ISSN : 1961-960X

Éditeur :

CNRS (UMR 7528 Mondes iraniens et indiens), Éditions de l'IFRI

Référence électronique

Sandra Aube, « Valentina Laviola, Martina Massullo (eds.), Maḥabbatnāma. Scritti offerti a Maria Vittoria Fontana dai suoi allievi per il suo settantesimo compleanno ", Abstracta Iranica [En ligne], Volume 42-43 | 2021, document 3, mis en ligne le 30 décembre 2021, consulté le 12 décembre 2022. URL : http:// journals.openedition.org/abstractairanica/53936; DOI : https://doi.org/10.4000/abstractairanica. 53936

Ce document a été généré automatiquement le 12 décembre 2022.

Tous droits réservés 


\title{
Valentina Laviola, Martina Massullo (eds.), Mahabbatnāma. Scritti offerti a Maria Vittoria Fontana dai suoi allievi per il suo settantesimo compleanno
}

\author{
Sandra Aube
}

\section{RÉFÉRENCE}

Valentina Laviola, Martina Massullo (eds.), Mahabbatnāma. Scritti offerti a Maria Vittoria Fontana dai suoi allievi per il suo settantesimo compleanno. Rome, Istituto per l'Oriente C.A. Nallino, 2020, 404 p., ISBN : 978-88-97622-69-7 (Pubblicazioni dell'Istituto per l'Oriente C.A. Nallino Nr. 125)

1 Ce volume d'hommage est édité par les soins de Valentina Laviola et Martina Massullo à l'occasion du $70^{\mathrm{e}}$ anniversaire de Maria Vittoria Fontana, professeure en archéologie et histoire de l'art islamiques à la Sapienza Università di Roma.

2 Il ouvre sur "Une pensée » de Roberta Giunta et Michele Bernardini, qui sont les initiateurs de ce livre («Un pensiero per Maria Vittoria», p.15-17), puis sur une caricature en hommage à l'intéressée par M. Bernardini (dont on ne cessera décidément d'admirer le talent, p.19). Cette entrée en matière est suivie de la bibliographie de M.V. Fontana de 1980 à 2020, puis de la préface des éditrices (« Tredici omaggi alla maestra: prefazione », p. 33-35).

3 Le livre rassemble ensuite 13 contributions, principalement écrites en Italien, qui émanent en grande part d'anciens étudiants de M. V. Fontana, qui a pris sa retraite un an après la parution de ce volume. Si une partie des auteurs sont des membres, décidément très actifs, du «Islamic Ghazni Project » (cf. les ouvrages récents recensés dans ce même numéro : Allegranzi, Laviola (2020) ; Laviola (2020); Allegranzi (2019); pour ne citer que les plus récentes parutions), il convient de relever la qualité et la 
diversité des thèmes proposés: études des objets (céramique, ivoire, etc.), de l'épigraphie monumentale et mobilière, de l'architecture et du décor architectural (stucs, marbres, etc.), mettant à l'honneur les études italiennes en histoire de l'art et en archéologie islamiques. Le spectre chronologique abordé est large, depuis les débuts de l'Islam jusqu'à des périodes récentes, de même que l'aire géographique traitée: du bassin de la Méditerranée orientale à l'Asie centrale. Deux articles sont consacrés au site de Ghazni (Fusaro, Laviola). Chaque article est suivi d'une bibliographie et d'illustrations en couleur.

5 - Viola Allegranzi, "Islamic inscriptions transposed in illustrated manuscripts: some notes in the Great Mongol Šāhnāma", p. 37-61.

6 - Silvia Armando, "Riscoprire un tesoro dimenticato: la cassetta in avorio di Civita di Bagnoregio. Osservazioni preliminary", p. 63-76.

7 - Andrea Luigi Corsi, "Discovery and display of a 'Seljuq' artefact: outlining the recent history of the Imāmzāda Karrār and its stucco decoration", p. 77-100.

8 - Michelina Di Cesare, "Bernard de Montfaucon e le Inscriptiones Arabicae", p. 101-138.

9 - Federica Duva, "Nuove considerazioni sulla datazione di alcuni siti del Darb Zubayda", p. 139-161.

10 - Agnese Fusaro, "Dealing with the Islamic glazed tiles from Ghazni again: new remarks on a still fascinating topic", p. 163-193.

11 - Giuseppe Labisi, "The Tārī Hâana Mosque of Damghan: a diachronic analysis", p. 165-229.

12 - Valentina Laviola, “Gli elementi in marmo del sistema idrico di Ghazni”, p. 231-261.

13 - Serenella Mancini, "Un frammento di moulded relief ware dalla cittadella di Erbil (Kurdistan iracheno)", p. 263-277.

14 - Martina Massullo, "Parole di luce. Note epigrafiche su una lampada da moschea di epoca mamelucca”, p. 279-303.

15 - Martina Rugiadi, “(Un)broken iconographies: the bird-and-quadruped ceramic fragment from the Masğid-i Ğum'a of Isfahan”, p. 305-344.

16 - Aila Santi, "The iconography of the Pseudo-Sēnmurv in Early Islamic art: the case of an enigmatic stamped roundel of the former Von-Osten collection", p. 345-375.

17 - Alessandro Taddei, "Aspetti della riproduzione di modelli nell'architettura mediobizantina il Katholikon di Hosios Loukas e i suoi metochia", p. 377-404.

\section{AUTEURS}

SANDRA AUBE

CNRS, CeRMI, Paris 